\title{
Experimental analysis of a car incorporating phase change material
}

\author{
Eduard Oró, Erik de Jong, Luisa F. Cabeza* \\ GREA Innovació concurrent, Edifici CREA, Universitat de Lleida, Pere de Cabrera s/n, 25001- \\ Lleida (Spain). \\ * Corresponding author: Phone: +34 973003576, Fax: +34 973003575, e-mail: 1cabeza@diei.udl.cat
}

\begin{abstract}
When in summer period vehicles, in particular cars, are parked outdoors their interior temperature increases dramatically even if the day is cloudy. Hence the thermal discomfort is obvious for the passengers when they get into the vehicle after a car park. In this paper the enhancement of the interior vehicle temperature conditions parked under the sun when a thermal energy storage (TES) system is placed inside the car is experimentally studied. The aim of this paper is to prove experimentally the benefit of using phase change materials (PCM) in terms of interior comfort for car passengers. The use of PCM results in lower air and steering wheel surface temperature and the increase of the thermal comfort of passengers. The benefit of the implementation of PCM inside cars was demonstrated since it maintained lower interior vehicle air and steering wheel surface temperatures.
\end{abstract}

Key-words: thermal comfort, vehicle, steering wheel, thermal energy storage, phase change material.

\section{INTRODUCTION}

The thermal comfort which is the state of mind that expresses satisfaction with the surrounding environment [1] of vehicular occupants is becoming an important issue since the time that people spend in both private and public transport has grown substantially. Therefore the interest in investigating and analysing the system and design requirements for good indoor and vehicle environments has increased. In that sense, the evaluation of the thermal comfort has been under investigation over the last 
years. Alahmer et al. [2] developed a comprehensible review of the different thermal comfort models through international standards to many research works.

The vehicle thermal situations are eminently sensitive to climatic conditions and the interior of the vehicles is a compartment where often thermal discomfort is obvious. In winter period, at least about five minutes are necessary before obtaining an acceptable temperature in the car if it has been parked outdoors. Similarly, in summer period, it is difficult to settle into a car if it has been exposed some time to solar radiation [3]. Once the passengers get into the vehicle during summer, they can experience thermal discomfort due to the high temperatures inside. Experimental measurements in Fremont, California, concluded that in a closed car the temperature increases with $22-27{ }^{\circ} \mathrm{C}$ within an hour [4]. Moreover, Dadour et al. [5] demonstrated that when a vehicle is parked in the sun, temperature levels in the cabin of the vehicle can be more than $20{ }^{\circ} \mathrm{C}$ above the ambient temperature. Therefore, in order to cool the car to reach comfortable temperatures values, a lot of air-conditioning power is needed. Obviously, this means more fuel consumption and therefore more $\mathrm{CO}_{2}$ emissions.

The physical factors affecting human thermal comfort depends upon four physical environmental variables: the air temperature, its relative humidity, the mean radiant temperature, and the relative air velocity [2]. And for thermal comfort in vehicles, the air temperature is the most important environmental variables. Another problem with excess heat inside the vehicles is heat strokes; this mostly occurs amongst young children and pets and leads to severe damage or even death. Grundstein et al. [6] indicate that even during cloudy days with lower ambient air temperatures, vehicle cabin temperatures may reach deadly levels and McLaren et al. [4] concluded the same statement after investigating heat stress from enclosed vehicles in children.

The use of thermal energy storage (TES) by the addition of phase change materials (PCM) is a possible solution to decrease air temperature rises inside the vehicles due to its ability in maintaining materials within a narrow temperature range by absorbing heat gains [7-9]. Some researchers have been investigating the addition of PCM in different places of vehicles. Tan et al. [10] studied experimentally the cold storage characteristics and the heat transfer regularity to meet the requirement of refrigeration in a liquefied gas (LNG) refrigerated vehicle. More related to the situation analysed in this 
manuscript, Ahmed et al. [11] modified the conventional method of insulation of the refrigerated truck trailer using PCM. An overall average daily heat flow reductions into the refrigerated compartment of $16.3 \%$ was observed.

The aim of this paper is to investigate experimentally the benefit of adding PCM into a car in terms of air temperature reduction and therefore comfort thermal improvement after parking the car under the sun for a period of time.

\section{MATERIALS AND METHOD}

\subsection{Car description}

The experimental set-up consists of a 5 door Seat Ibiza 2007 as Figure 1 shows. The dimensions of the car used are presented in Table 1. In this research the experimentation has done at the same location and under similar boundary conditions, therefore only the air temperature will be considered to evaluate thermal comfort inside the car. The air temperature inside the vehicle, the steering wheel surface temperature, the ambient temperature (shade and sunlight) and the PCM temperature were measured and monitored continuously using Pt-100 (1/5 DIN class B) and a data logging system.

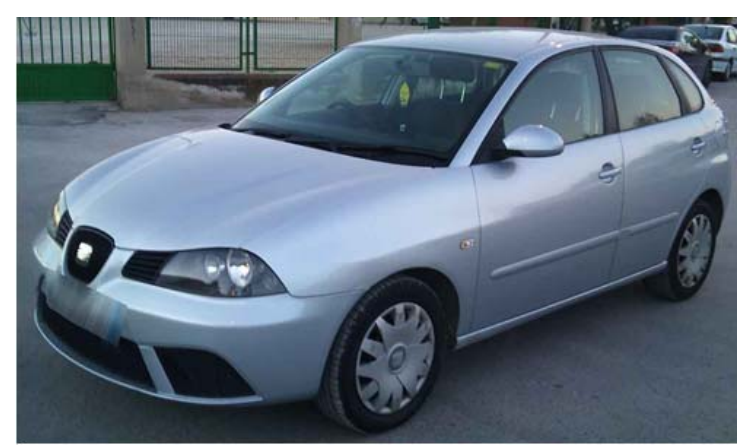

Figure 1. Vehicle (Seat Ibiza) used in the experimentation. 
Table 1. Characteristics of the car used in the experimentation.

\begin{tabular}{lc}
\hline Characteristics & Value \\
\hline Long & $3977 \mathrm{~mm}$ \\
Width & $1419 \mathrm{~mm}$ \\
High & $1445 \mathrm{~mm}$ \\
Total volume & $2.35 \mathrm{~m}^{3}$ \\
Trunk volume & $0.25 \mathrm{~m}^{3}$ \\
Internal useful volume & $2.1 \mathrm{~m}^{3}$ \\
\hline
\end{tabular}

In order to have a correct air map temperature of the vehicle cabin the car was divided in five areas, front right, front left, back right, back left and roof. Moreover, different air temperature measurements were done in the height direction (feet, bottom, back and head) as Figure 2 shows. This implementation of the temperature sensors allow to determine the thermal comfort of different body parts and therefore each passenger can independently be examined. All the temperature sensors located inside the car were shaded using a paper cylinder to prevent higher temperatures due to direct solar radiation. All the temperature sensors were previously calibrated from 10 to $70{ }^{\circ} \mathrm{C}$ in MICROCAL T100 equipment of an accuracy of $0.1{ }^{\circ} \mathrm{C}$.

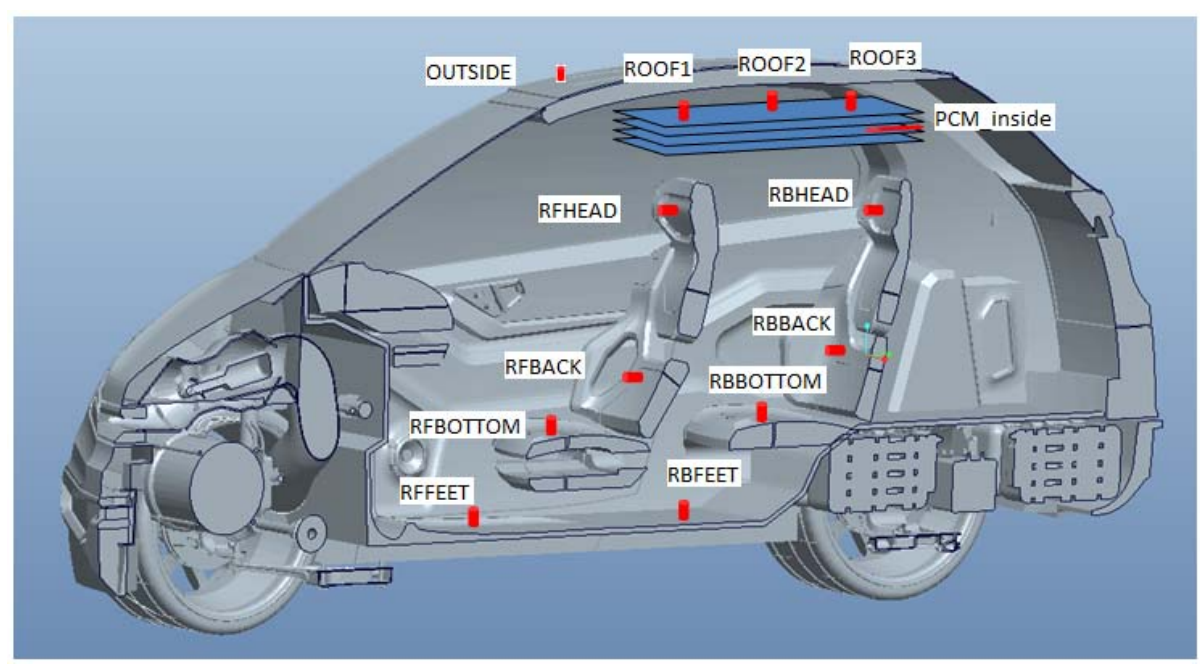

Figure 2. Location of the air temperature sensors located in the right side of the vehicle.

\subsection{Phase change material}

In the experimentation a commercial PCM (RT-27) from Rubitherm was used. The PCM was used in the vehicle cabin, placed under the roof of the car, and in the steering 
wheel. The PCM was placed under the roof in order to get a large area of exchange between the internal air and the PCM and therefore have a good thermal heat exchange. Moreover, it is more practical since the roof is the largest available surface in vehicles. In order to hold the PCM plates under the roof of the car, an aluminium structure was built which allows changing easily the PCM plates. The total PCM used in the vehicle cabin was $4 \mathrm{~kg}(4.551)$, occupying $0.22 \%$ of their internal volume. The PCM was available as a bulk material and therefore an encapsulation had to be made using aluminium plates for the cabin. On the other hand, the PCM used on the steering wheel was encapsulated with a plastic bag in order to give to it the correct shape.

The thermophysical properties given by the manufacturer are shown in Table 2. Moreover, Differential Scanning Calorimetry (DSC) analysis was performed using a DSC-822e commercialized by Mettler Toledo. The analysis was performed using a dynamic method from 5 to $50{ }^{\circ} \mathrm{C}$ and a heating rate of $1{ }^{\circ} \mathrm{C} / \mathrm{min}$. the amount of sample studied was around $15 \mathrm{mg}$ in an aluminium crucible under $\mathrm{N}_{2}$ atmosphere. Figure 3 shows the specific heat and the enthalpy curve in function of the temperature.

Table 2. Physical characteristics for RT-27 (as given by the manufacturer [12]).

\begin{tabular}{llc}
\hline Physical properties & Nomenclature & RT-27 \\
\hline Density at $20^{\circ} \mathrm{C}$ & $\rho_{\text {at } 20^{\circ} \mathrm{C}}$ & $880 \mathrm{~kg} \mathrm{~m}^{-3}$ \\
Density at $40{ }^{\circ} \mathrm{C}$ & $\rho_{\text {at } 40^{\circ} \mathrm{C}}$ & $770 \mathrm{~kg} \mathrm{~m}^{-3}$ \\
Temperature of fusion & $\mathrm{T}_{\mathrm{PCM}}$ & $25-28{ }^{\circ} \mathrm{C}$ \\
Latent heat & $\mathrm{H}$ & $184 \mathrm{~kJ} \mathrm{~kg}^{-1}$ \\
Thermal conductivity & $\lambda$ & $0.2 \mathrm{~W} \mathrm{~m}^{-1} \mathrm{~K}^{-1}$ \\
\hline
\end{tabular}

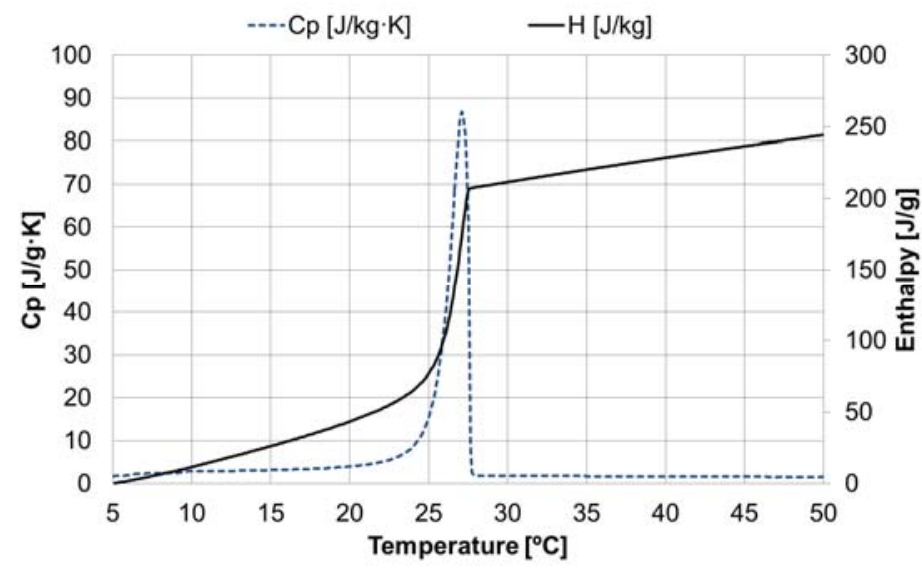

Figure 3. RT-27 specific heat and enthalpy in function of temperature. 


\subsection{Weather conditions comparison}

As only one car was available to perform the measurements, the experimentation with and without PCM had to be done in different days. Therefore and in order to compare the results with and without PCM, similar weather conditions needed to be found. The experiments were done always at midday when most dramatic situation can occur. Notice that only similar days in terms of ambient temperature and solar radiation are considered to be compared. Preliminary experiments showed that measurements with almost the same outside temperature can be compared each other since the cabin vehicle difference temperature is below $1{ }^{\circ} \mathrm{C}$.

\subsection{Experimental procedure}

Before starting the experimentation the PCM (when it is placed inside the car) has to be solidified and the cabin should be at homogeneous temperature around $20{ }^{\circ} \mathrm{C}$. This is done using the air conditioning system of the car and placing it inside a warehouse where the solar radiation is not affecting the vehicle conditions. Then the car is parked in the sun for 2 hours simulating a normal car park anywhere. This paper only deals with the conditions that the users would find after letting the car being heated up by the sun. Therefore, in order to evaluate the benefit of introducing PCM inside the car, the results with and without PCM are compared. The front of the car was placed towards the north in order to prevent differences in the experimentation between different days in terms of solar radiation incidence inside the car, especially to the frontal part of the vehicle.

Similar procedure is used when the addition of PCM in the steering wheel is studied. Half of the steering wheel is covered by PCM while the other half remains at normal conditions. Then both surface temperature of each half of the steering wheel were measured. Since the car was placed to the north, the direction of the solar radiation affects by equal any part of the steering wheel. This phenomenon was checked for each experimentation in order to ensure that the results were correct. 


\section{RESULTS AND DISCUSSION}

\subsection{Thermal performance analysis of the interior}

The measurements were performed during June and July of 2012. Many experiments have been performed in order to have comparable results in terms of similar outside temperature. Here only those comparable experiments are presented and discussed.

As expected and due to air stratification the temperature at the roof is the highest, being on average from 5 to $10^{\circ} \mathrm{C}$ higher than the temperature at the head position. Similarly, the air temperature in the feet area was lower than the rest of the air temperature measured. Notice that the temperature difference inside the car is really important, being in some experiments higher than $20^{\circ} \mathrm{C}$. Figure 4 and Figure 5 show the air temperature at different height position (feet, bottom, back, head and roof) in the front passenger seat during a car parking in the sun without and with PCM, respectively. The effect of using PCM is clearly demonstrates since lower temperatures are reached when PCM is implemented. Due to the location of the PCM under the roof, the upper part of the car is showing higher differences between scenarios. While the roof, head and back of the reference system reach temperatures of 56,46 and $46^{\circ} \mathrm{C}$, respectively, the use of PCM results in lower temperatures of 52,44 and $42{ }^{\circ} \mathrm{C}$. That means a temperature reduction between 2 and $4{ }^{\circ} \mathrm{C}$. Even though the lower parts of the car (bottom and feet) are further away from the PCM position, a temperature difference of $2{ }^{\circ} \mathrm{C}$ is also observed.

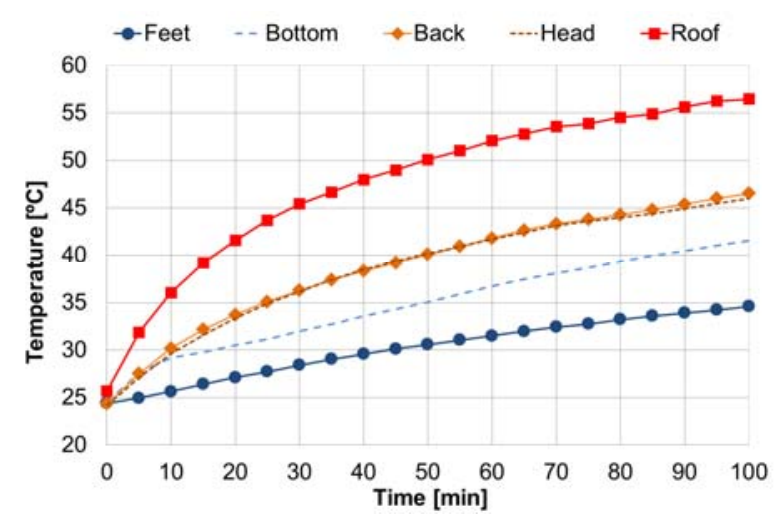

Figure 4. Air temperature at different height in the front passenger seat. 


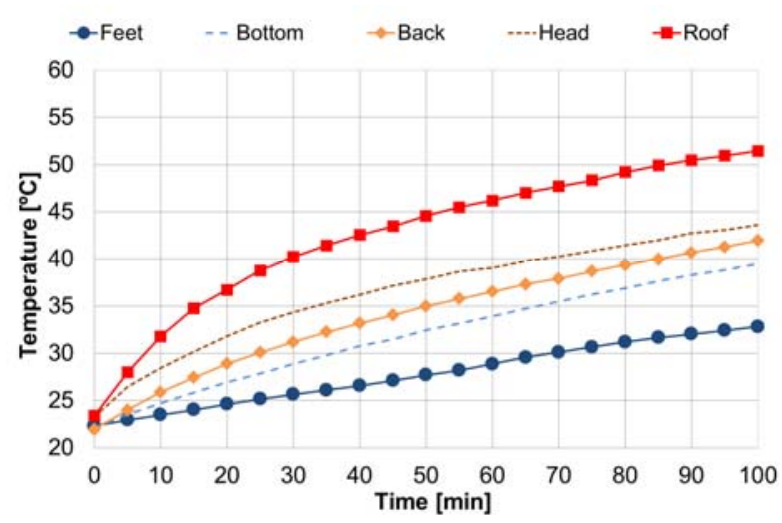

Figure 5. Air temperature at different height in the front passenger seat when PCM is placed in the car.

Figure 6 shows the PCM temperature and the average air temperature of different experiments showing that the PCM is always under phase change. After 80 minutes the phase change finishes, hence the PCM cannot store more energy as latent heat and therefore the ambient temperature of the car increases faster. This phenomenon is direct related to the quantity of PCM used in the experimentation which was $4 \mathrm{~kg}$, representing $0.22 \%$ of the internal volume of the car. In order to further control the ambient temperature increase after 80 minutes more PCM is needed. Also with the incorporation of more PCM lower air temperatures will be reached at the initial period of the experimentation. However, the optimum quantity of PCM in function of climate condition in terms of location and period of the year and time of parking has to be characterised using a mathematical model.

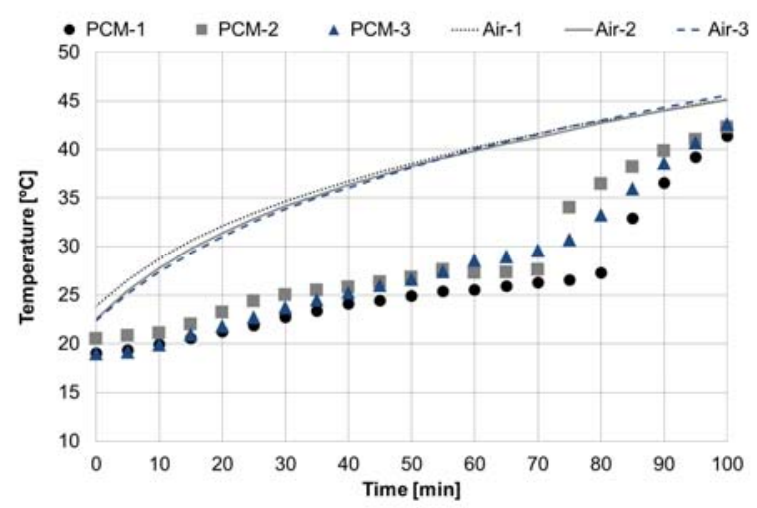

Figure 6. PCM temperature and average air temperature for different experimentation.

Figure 7 shows the air temperature profile during 100 minutes of the front and back right side of the vehicle. Initially both experiments started at similar air temperature (20 ${ }^{\circ} \mathrm{C}$ ) and after letting the car under the sun the air temperature started to go up. Notice 
that when PCM was placed under the roof of the car, the air temperature inside the vehicle was lower and therefore when the passengers would get inside it the thermal comfort would be better than in a normal car situation (without PCM).

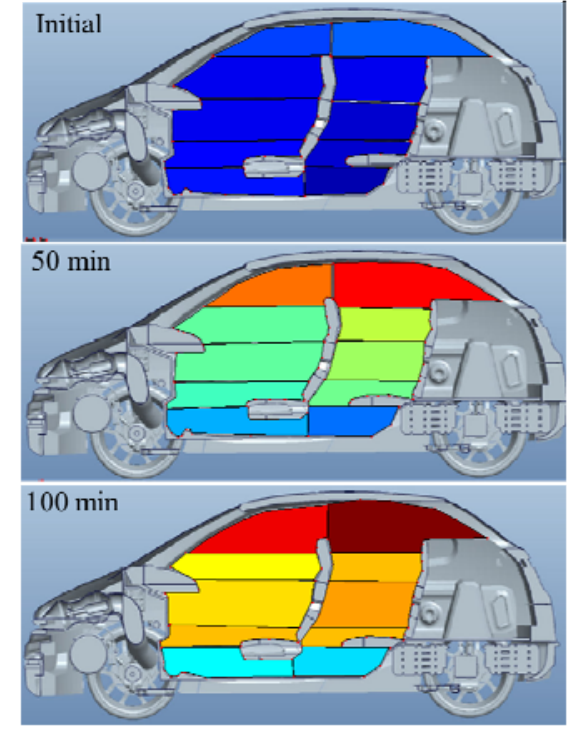

Withourt PCM
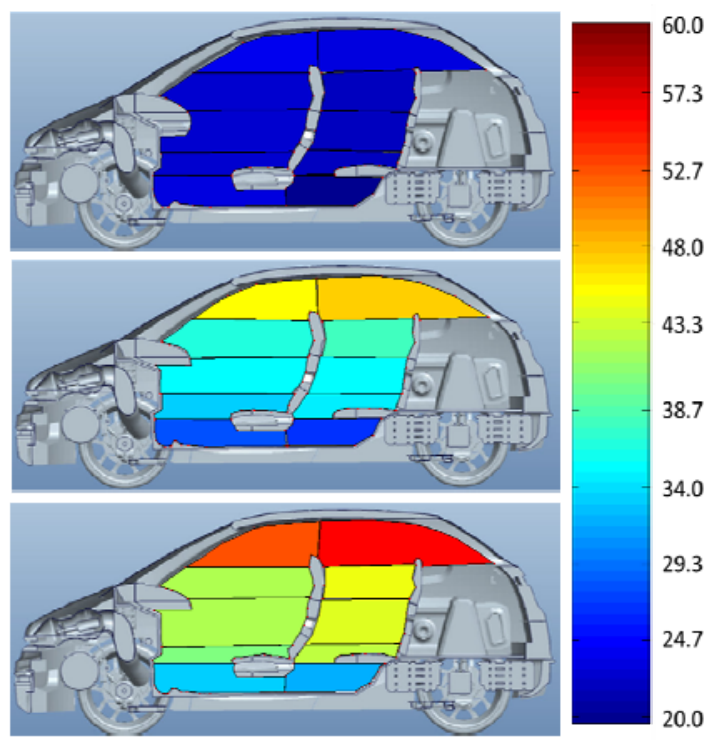

With PCM

Figure 7. Air map temperature of the vehicle at different times (colour figure in the electronic version of the paper).

\subsection{Thermal performance analysis of the steering wheel}

The steering wheel surface temperature with and without PCM was measured while the vehicle is under the sun for a time period of 2 hours. Due to the symmetry of the steering wheel, and ensuring that the direction of the solar radiation affects equally, both experiments (with and without PCM) could be done at the same time by adding PCM to the half part of the steering wheel. All the temperature sensors located inside the car were shaded using a paper cylinder to prevent higher temperatures due to direct solar radiation.

Figure 8 shows the temperature variation of the steering wheel surface for two different experiments. The difference between both experiments was the ambient temperature where in experiment 1 (E1) was higher, simulating a summer day, than experiment 2 (E2) which was performed in a cloudy day. Notice that in a summer day, the steering wheel temperature can reach above $60{ }^{\circ} \mathrm{C}$ in 90 minutes, almost $70{ }^{\circ} \mathrm{C}$ after 2 hours. 
This value is close to the burn threshold temperature of $70{ }^{\circ} \mathrm{C}$ if the surface would be hold for 10 seconds [13]. Therefore, the addition of PCM on the steering wheel not only is beneficial in terms of thermal comfort but in terms of driver safety.

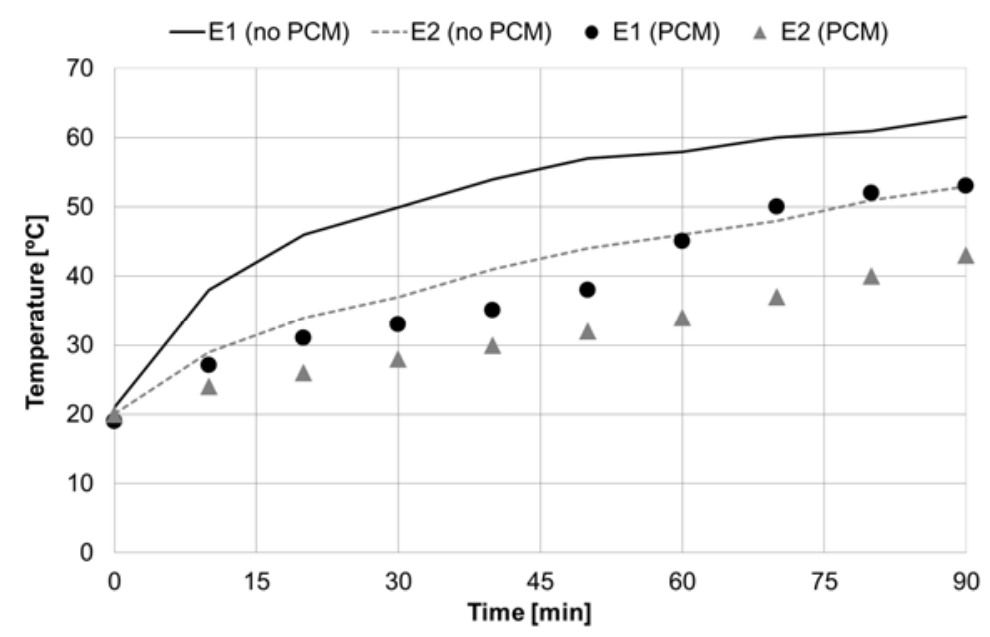

Figure 8. Steering wheel surface temperature with and without PCM.

\section{CONCLUSIONS}

The inlet vehicle temperature can get easily high during summer and even winter period just when the car is placed for short term outside. This fact could affect to the thermal comfort of the passengers and could cause heat strokes amongst young children. Here, the benefits in terms of thermal comfort using phase change materials (PCM) inside a car have been analysed experimentally. The PCM was placed under the car roof due to the high heat exchange area to the cabinet. Moreover, PCM was placed on the steering wheel in order to reduce the surface temperature after some time under the sun.

When PCM was added to the car, representing only $0.22 \%$ of the internal volume, the results showed significant decrease in air temperature after a car park of 2 hours. Therefore, the benefit of using PCM was clearly demonstrated. Moreover, the steering wheel surface temperature could also be significantly reduced (from 5 to $10{ }^{\circ} \mathrm{C}$ ) by placing the PCM on it. The optimum quantity of PCM in function of climate condition in terms of location and period of the year and time of parking has to be characterised using a mathematical model. The experimental data presented in the manuscript will be used to validate a numerical model in further research work. 


\section{ACKNOWLEDGEMENTS}

The work is partially funded by the Spanish government (ENE2011-22722). The authors would like to thank the Catalan Government for the quality accreditation given to their research group GREA (2009 SGR 534). Eduard Oró would like to thank the University of Lleida for his research fellowship.

\section{REFERENCES}

[1] ANSI/ASHRAE Standard 55, Thermal environmental conditions for human occupancy.

[2] Alahmer A, Mayyas A, Mayyas AA, Omar MA, Shan D. Vehicular thermal comfort models; a comprehensive review. Appl Therm Eng 2001; 31:995-1002.

[3] Mezrhab A, Bouzidi M. Computation of thermal comfort inside a passenger car compartment. Appl Therm Eng 2006;26:1697-1704.

[4] McLaren C, Null J, Quinn J. Heat stress from enclosed vehicles: moderate ambient temperatures causes significant temperature rise in enclosed vehicles. Pediatrics 2005;116:109-112.

[5] Dadour IR, Almanjahie I, Fowkes ND, Keady G, Vijayan K. Temperature variations in a parked vehicle. Forensic Sci Int 2011;207:205-211.

[6] Grundstein A, Meentemeyer V, Dowd J. Maximum vehicle cabin temperatures under different meteorological conditions. Int J Biometeorol 2009;53:255-261.

[7] Zalba B, Marín JM, Cabeza LF, Mehling H. Review on thermal energy storage with phase change: materials, heat transfer analysis and applications. Appl Therm Eng 2003;23:251-283.

[8] Farid MM, Khudhair A, Razak SA, Al-Hallaj S. A review on phase change energy storage: materials and applications. Energy Convers Manage 2004;45:1597-1615.

[9] Oró E, de Gracia A, Castell A, Farid MM, Cabeza LF. Review on phase change materials (PCMs) for cold thermal energy storage applications. Appl Energy 2012;35:984-991.

[10] Tan H, Li Y, Tuo H, Zhou M, Tian B. Experimental study on liquid/solid phase change for cold energy storage of Liquefied Gas (LNG) refrigerated vehicle. Energy 2010;35:1927-1935. 
[11] Ahmed M, Meade O, Medina MA. Reducing heat transfer across the insulated walls of refrigerated truck trailers by the application of phase change materials. Energy Convers Manage 2010;51:383-392.

[12] www.rubitherm.com [Acces March 2013]

[13] CENELEC GUIDE 29. Temperatures of hot surfaces likely to be touched, Guidance document for Technical Committees and manufacturers, first ed., 2007. 